\title{
A LITERATURA INFANTIL NO PROCESSO DE INCLUSÃO DE ALUNOS COM DEFICIÊNCIA AUDITIVA
}

\author{
Carla Georgia Travassos Teixeira Pinto ${ }^{1}$ \\ Marcia Cristina Ribeiro Gonçalves Nunes ${ }^{2}$
}

\begin{abstract}
RESUMO
O presente trabalho focaliza numa experiência de inclusão de aluno surdo em escola regular de ensino, sendo que o deficiente auditivo possui privação auditiva e como consequência disso o processo de aquisição e desenvolvimento de fala e linguagem oral sofre atraso. Dentro desse contexto a linguagem é elemento crucial no desenvolvimento linguístico-cognitivo do sujeito e dessa forma torna-se de grande relevância no processo de aprendizagem. Em sujeitos ouvintes a aprendizagem da linguagem escrita se dá através da linguagem oral, no entanto, no sujeito com deficiência auditiva, esse processo sofre um significativo atraso tanto na leitura como na escrita, já que ambas são produções consideradas abstratas para estes. O presente estudo possui como objetivo divulgar através da literatura infantil possibilidades de facilitar o desenvolvimento de interpretação e compreensão de textos pelos sujeitos que possuem deficiência auditiva. A metodologia do presente estudo foi desenvolvida tendo como orientação a tendência bilíngue, com seis deficientes auditivos, com idades entre 7 a 12 anos, todos alunos da Escola Municipal de Ensino Fundamental Gabriel Lage da Silva. O percurso metodológico foi construído em três etapas: leitura de texto usando a Língua Brasileira de Sinais, dramatização e por fim produção textual. Como apreciação avaliativa da dinâmica os respectivos sujeitos melhoram a compreensão e interpretação de texto consideravelmente, ainda que com dificuldades gramaticais e sintáticas.
\end{abstract}

Palavras-Chave: Literatura infantil. Diversidade. Educação inclusiva. Ensino regular.

\begin{abstract}
This paper focuses on an experience of inclusion of deaf students in a regular school, with the impaired hearing deprivation and as a consequence the process of acquisition and development of speech and oral language is delayed. Within this context, language is a crucial element in the subject's linguistic-cognitive development and thus becomes of great relevance in the learning process. In hearing subjects the learning of written language occurs through oral language, however, in the impaired hearing subject, this process suffers a significant delay in both reading and writing, since both are considered abstract productions for them. This study aims to publish through children's literature, possibilities to facilitate the development of interpretation and understanding of texts by subjects who have hearing impairment. The methodology of the present study was developed based on bilingual tendency, with 6 (six) impaired hearing ones, aged 7 to 12 years old, all students of Gabriel Lage da Silva Municipal Elementary School. The methodological course was built in three stages: text reading using Brazilian Sign Language (Libras), role playing and finally textual production. As an evaluative appreciation of the dynamics the respective subjects improve the comprehension and interpretation of text considerably, even with grammatical and syntactic difficulties.
\end{abstract}

Keywords: Children's Literature. Diversity. Inclusive Education. Regular Education.

\section{CONCEITUANDO A SURDEZ}

\footnotetext{
${ }^{1}$ Mestranda no Programa de Pós-Graduação em Comunicação, Linguagem e Cultura na Universidade da Amazônia - PPGCLC/UNAMA. Email: carlageorgia24@yahoo.com.br

2 Doutora em História e Professora do Programa de Pós-Graduação em Comunicação, Linguagem e Cultura na Universidade da Amazônia - PPGCLC/UNAMA. Email: marcianunes2011 @ gmail.com
} 
A literatura internacional aponta diferenças nos âmbitos da audiologia entre os termos deficiente auditivo e surdo. No Brasil essa distinção não ocorre, evidencia-se, que os usos dessas terminologias são definidos pelos conceitos advindos da posição filosófica que se possui sobre a surdez. A luz do modelo médico e de uma abordagem oralista, o sujeito portador de uma perda de audição, comumente é denominado de "deficiente auditivo". Segundo Skliar (1998), árduo defensor do bilinguismo, a surdez é estabelecida a partir de quatro níveis diferentes a saber: como diferença política, como experiência visual, como caracterização de múltiplas identidades e como deficiência. Neste caso, como deficiência, Skliar (1998) fala das estratégias pedagógicas e o discurso da educação bilíngue conservam-se na área da educação especial, mantendo o sujeito surdo como excepcional, não distinguindo a educação especial da educação de surdos.

Neste artigo, iremos reputar o surdo como o sujeito que possui uma perda de audição, apartado de qualquer definição da audiologia. Neste sentido, discutiremos a partir de pessoas que detêm valores e condições sócio-educacionais distintas dos ouvintes. É importante ressaltar também que, a marca não habita na terminologia, mas no modo como o surdo é nomeado, como ele é tratado, na instituição escolar, no contato com o mundo ouvinte e os diversos obstáculos que este precisa ultrapassar para tentar garantir os seus direitos e deveres de cidadão dentro de uma sociedade. Além disso, a comunidade surda adulta brasileira tem se posicionado contra o termo "deficiente auditivo", pela implicação de "incapacidade", deliberou-se, em consideração a eles, empregar a nomenclatura surdo a sujeitos que são portadores de uma perda de audição.

Quando falamos de linguagem assumimos postura sociointeracionista. Através da relação adulto/criança ou ainda criança/criança, o sujeito responde, constrói e sistematiza seu conhecimento. Ao difundir seus conhecimentos para crianças, o adulto acaba por envolver-se no processo de cognição e oportuniza o desenvolvimento linguístico da mesma. No contexto de diálogo com o outro, a linguagem é estruturada em conjunto, e, por intercessão de alguns processos dialógicos, a criança converte-se em um ser na linguagem. E a ausência de qualquer modalidade de linguagem prejudica de modo relevante no desenvolvimento do indivíduo, sendo capaz e acarretar modificações comportamentais com sequelas sérias em relação à formação de identidade do surdo.

$\mathrm{Na}$ criança ouvinte, a conquista da linguagem oral ocorre de maneira espontânea em circunstância contextualizada e motivadora. Desde o nascimento, a criança elabora sons através do choro e de vocalizações. O adulto responde a essas projeções e a criança satisfaz o 
desejo em obter respostas sonoras do mundo e pessoas que a cercam. Desta forma, a criança ouvinte, por meio do controle auditivo, inicia o processo de compreensão dos sons que são usados para se comunicar. Todavia, na criança surda as emissões sonoras assumem forma reflexa, não produzindo significado comunicativo às vocalizações, tendo como resultado a diminuição das mesmas.

\section{O UNIVERSO LITERÁRIO DIALOGANDO COM A INCLUSÃO DE ALUNOS SURDOS}

Refletindo acerca da Educação inclusiva entendemos que existem dois princípios básicos para se considerar com relação às demandas relacionadas ao acesso e à permanência com sucesso de discentes surdos. Salientamos que tais princípios estão registrados nas leis do país, especialmente na convenção sobre os direitos das pessoas com deficiência (BRASIL, $2009^{a}$ ), que apresentou um novo paradigma para a educação no Brasil.

Precisamos entender que a universalização e a democratização nas escolas necessitam urgentemente ser analisadas dentro de um contexto real, sem protecionismo, nem atitudes paternalistas, no entanto, respeitando as diferenças e as diversidades. Dentro desse contexto, não estamos falando de simplificar os caminhos de acesso à educação, à saúde e à moradia, estamos aqui insistindo em algo de grande significado para o discente surdo, estamos falando em oferecer condições de igualdade. Neste sentido, entendemos que acreditar na capacidade e na aptidão em aprender e produzir conhecimentos, de sujeitos com formas diferentes de se inter-relacionar com o mundo e com a erudição; é constatar, explicitamente, a essência do princípio da universalização.

Disponibilizar possibilidades de igualdade é assunto hermético, todavia, precisamos ponderar sobre a ampliação das garantias legais e reais de acesso das pessoas surdas à escola regular, de forma honesta, respeitável e democrática. Também, se faz necessário, ultrapassar o grande abismo gerado historicamente no suposto coletivo da sociedade em geral e, de modo preciso, no âmbito acadêmico, o qual compreende significativas inquietações e relutância à inclusão dessas pessoas nesse ambiente restrito a um grupo privilegiado do país. Na tessitura dessa narrativa, entendemos que as universidades detêm um papel importante na conquista da reedificação desse imaginário, numa interpretação mais crítica e fundamentada em outras convicções como o da democratização das oportunidades e possibilidades de vencer as dificuldades. Acreditamos, no sujeito pleno de talentos e repleto de possibilidades para rescindir com as limitações e vencer esse paradigma fatídico e excludente. 
Neste cenário, destacamos a importância do professor do Ensino Fundamental ler histórias aos seus alunos. Ademais, a leitura de histórias configura-se em um dos elementos fundamentais para o início do letramento das crianças, instituindo-se em um dos objetivos para toda a Educação Infantil. Sendo assim, o trabalho com leitura e interpretação de histórias favorece o desenvolvimento cognitivo e biopsicossocial, contribuindo no processo de ensinoaprendizagem, já que os discentes surdos podem sentir e vivenciar os conteúdos atitudinais debatendo/reconhecendo as regras do mundo dos adultos, conhecendo para depois comportarse adequadamente às determinações sociais cotidianas de cada grupo em que eles se firmam.

Notemos que a contação de história representa um momento significativo e de relevante contribuição no desenvolvimento, inclusive do discente surdo. Os discentes surdos ampliam seus conhecimentos por meio da leitura e experiência visual, todavia, sozinhos o caminho para se formar leitores se torna difícil. Por serem leitores visuais, precisam de imagens, de textos e do livro para que consigam fortalecer sua competência visual e de leitura. Os discentes surdos necessitam descobrir sentidos que transcenda a essência da leitura escolar e, preferencialmente, deve trazer do lar um convívio afetivo com os livros, formado com a família por meio da Língua Brasileira de Sinais (Libras). Assim sendo, levanta-se um questionamento instigante: se a contação de história é determinante para o desenvolvimento cognitivo e emocional de todo discente, assim como oportunizar vivências de contação de histórias para o discente surdo?

Diante dessa perspectiva, consolidou-se como objetivo nosso divulgar material didático para alunos surdos em processo de alfabetização. Através do livro "Os ecopiratas" o qual é traduzido para Libras, iniciamos nosso projeto de inclusão permeado pelo paradigma do século XXI que fomenta a concepção de inclusão de todos os sujeitos nos diferentes grupos sociais, e a instituição escolar representa um dos pilares de erradicação de barreiras convertendo-se em fundamento primordial (MENDES, 2006). É importante enfatizarmos que entre os pilares de acessibilidade, a comunicação destaca-se como sendo um dos mais significativos no processo educacional do discente surdo. Martins e Giroto (2011), chamam a nossa atenção para:

Infelizmente, grande parte dos alunos surdos, frequentadores de classe inclusiva, no ensino regular, não tem acesso aos conhecimentos valorizados culturalmente pela escola, pelo fato de não terem se apropriado de um sistema linguístico, seja este auditivo-verbal ou gesto-visual, no caso de uma língua de sinais (MARTINS e GIROTO, 2011, p. 3) 
Salles, Faustich e Carvalho (2004) justificam o fracasso escolar dos discentes surdos em decorrência de uma gama de fatores que possui em comum a condição de ser obrigado a ultrapassar a deficiência sendo desagradável adquirir as mesmas habilidades dos discentes ouvintes. Somado a isso, Dorziat (1999), destaca o fato de os discentes surdos serem tardiamente instruídos a utilizar a Libras para se comunicarem, pois frequentemente, nascem em uma família de ouvintes, os quais não possuem o conhecimento da língua de sinais e, ao receber o diagnóstico da surdez, por vezes até suspendem o ato de conversar com a criança, o que a prejudica ainda mais, já que a conversa estimula a leitura labial e também reforça laços afetivos familiares. Neste sentido, os autores Bandini, Oliveira e Souza (2006), chamam atenção para o fato de:

[...] pode-se verificar que o uso de uma língua, mesmo que na modalidade visoespacial, confere ao indivíduo o acesso a todos os recursos que a linguagem pode proporcionar, isto é, a organização do pensamento, a capacidade de lidar com coisas e fatos mesmo à distância, a habilidade de abstrair e manusear símbolos e finalmente de se comunicar com outras pessoas, estabelecendo uma vida social e política sem restrições. (BANDINI, OLIVEIRA e SOUZA, 2006, p. 52).

Por consequência, decidimos utilizar material didático traduzido em Libras não apenas por ser mais compreensível ao discente que possui o entendimento dessa língua, mas também para ajudar àqueles que estão desenvolvendo a mesma. Sendo assim, é necessário elucidar que há três tendências na educação do surdo: educação oral, comunicação total e utilização das línguas nacionais de sinais (DORZIAT, 1999; PEREIRA, 2005; BANDINI, OLIVEIRA e SOUZA, 2006). Para melhor entendimento, Martins e Giroto (2011) esclarecem as concepções centrais de cada uma dessas habilidades teórico- filosóficas:

O Oralismo que defende o uso exclusivo da língua oral na interação surdos/ouvintes, enfatiza a importância do uso de habilidades auditivas como pré-requisitos para o desenvolvimento da linguagem, pois seus precursores propõem um trabalho intensivo de estimulação auditiva, o qual deve iniciar-se o mais cedo possível na vida da criança surda (MARTINS e GIROTO, 2006, p. 8-9).

A abordagem da Comunicação Total, que apresenta como proposta a valorização dos mais variados recursos que podem facilitar o acesso do surdo à linguagem oral e escrita, propõe práticas bimodais/simultâneas, das quais fazem parte sinais e fala, possibilitando ao surdo o acesso mais fácil às modalidades oral e escrita da língua majoritária (MARTINS e GIROTO, 2006, p. 8-9).

[...] a filosofia de educação bilíngue tem proposto o acesso da criança a duas línguas: a de sinais e a oficial do país, neste caso na modalidade escrita. Contrária à filosofia da Comunicação Total, nesta visão, ambas as línguas não podem ser usadas simultaneamente pelo fato de possuírem estruturas diferentes. Seus proponentes concebem os sinais como a "língua natural" dos surdos, sendo que estes são considerados como pertencentes, na maioria dos casos, a uma comunidade distinta daquela a que pertencem os ouvintes (MARTINS e GIROTO, 2006, p. 8-9). 
Não iremos nos deter em discutir as vantagens e desvantagens dessas tendências. Não obstante, devemos lembrar que a língua de sinais é reconhecidamente a língua materna do discente surdo. E foi justamente pensando na importância do acesso a materiais didáticos traduzidos para língua de sinais, que buscamos compreender que acessibilidade não dever ser concebida apenas em uma perspectiva. Segundo Sassaki (2005, p. 22-23), há seis dimensões de acessibilidade saber: arquitetônica, comunicacional, metodológica, instrumental, programática e atitudinal:

\begin{abstract}
Acessibilidade comunicacional, sem barreiras na comunicação interpessoal (face a face, língua de sinais, linguagem corporal, linguagem gestual, etc.), na comunicação escrita (jornal, revista, livro, carta, apostila, etc., incluindo textos em braile textos com letras ampliadas para quem tem baixa visão, notebook e outras tecnologias assistivas para comunicar) e na comunicação virtual (acessibilidade digital). Acessibilidade instrumental, sem barreiras nos instrumentos e utensílios de estudo (lápis, caneta, transferidor, régua, teclado de computador, materiais pedagógicos), de atividades da vida diária (tecnologia assistiva para comunicar-se, fazer a higiene pessoal, vestir, comer, andar, tomar banho, etc.) e de lazer, esporte e recreação (dispositivos que atendam às limitações sensoriais, físicas e mentais, etc.) (SASSAKI, 2005, p. 22-23).
\end{abstract}

Podemos afirmar que é um equívoco pensar que a pessoa surda não se comunica ou mesmo não possui uma língua, uma vez que a comunidade surda possui seu modo particular de se comunicar:

\begin{abstract}
As línguas de sinais são consideradas línguas naturais e, consequentemente, compartilham uma série de características que lhes atribui caráter específico e as distingue dos demais sistemas de comunicação. As línguas de sinais são, portanto, consideradas pela linguística como línguas naturais, ou como um sistema linguístico legítimo e não como um problema de surdo ou como uma patologia da linguagem (QUADROS e KARNOPP, 2004, p. 30).
\end{abstract}

Todavia, como sublinham Torres, Mazzoni e Melo (2007), não são todos os discentes surdos que conseguiram ter acesso a Libras e tiveram a possibilidade de aprendê-la; por vezes, somente quando adentram a escola apreenderão. Portanto, a educação do discente surdo deve ser consolidada como bilíngue, ou seja, em Libras, sua língua materna, e em Língua Portuguesa, a língua da sociedade em que esse discente está incorporado. Salles, Faustich e Carvalho (2004) alertam para:

Recomenda-se que a educação dos surdos seja efetivada em língua de sinais, independentemente dos espaços em que o processo se desenvolva. Assim, paralelamente às disciplinas curriculares, faz-se necessário o ensino de língua portuguesa como segunda língua, com a utilização de materiais e métodos específicos no atendimento às necessidades do surdo. Nesse processo, cabe ainda considerar que os surdos se inserem na cultura nacional, o que implica que o ensino 
da língua portuguesa deve considerar temas que contribuem para a afirmação e ampliação das referências culturais que os identificam como cidadãos brasileiros (SALLES, FAUSTICH e CARVALHO, 2004, p. 47).

O Decreto $\mathrm{n}^{\mathrm{o}}$ 5.626, de dezembro de 2005 (BRASIL, 2005), frisa que a língua portuguesa é a segunda língua do discente surdo e que a transmissão de conhecimentos dessa modalidade escrita, na qualidade de segunda língua, deve ser integrada como disciplina curricular nos cursos de formação de professores para educação infantil e anos iniciais do ensino fundamental. Salles, Faustich e Carvalho (2004), destacam que:

O letramento é, portanto, condição e ponto de partida na aquisição da língua oral pelo surdo, o que remete ao processo psicolinguístico da alfabetização e à explicitação e construção das referências culturais da comunidade letrada. Essa tarefa é, porém, menos árdua se a modalidade escrita da língua oral é adquirida como L2, sendo a língua de sinais adquirida como L1, cabendo desenvolver estratégias de ensino que levam em consideração a situação psicossocial do surdo, em particular sua condição multicultural (SALLES, FAUSTICH e CARVALHO, 2004, p. 77-78).

Nesta condição, evidencia-se a importância da Libras no sentido do discente surdo conecte-se à cultura escolar. E assim, esse discente possa alicerçar-se como sujeito, conforme os teóricos. Vigotski (1997) e Alves (2003), afirmam que é imprescindível que o discente surdo tenha acesso à comunicação empregada pela sociedade em que está introduzido.

\section{SALA DE LEITURA: LUGAR DE INCLUSÃO}

A audição desempenha papel primordial no processo de desenvolvimento da linguagem, por conseguinte, o discente surdo possui atraso de aquisição e desenvolvimento de fala e linguagem oral. Quanto maior o grau de perda auditiva, maiores poderão ser os prejuízos para a aquisição da linguagem oral e do processo de aprendizagem. Importante avaliar dentro de um contexto maior o grau de perda auditiva, a idade que foi feito o diagnóstico e analisar o contexto familiar e social em que o sujeito está incluído e como se sucede o seu processo educacional.

É importante ressaltar, que há maior dificuldade para o discente surdo tomar posse da linguagem escrita. Desta forma, enfatiza Buffa (2002), que sujeitos surdos possuem maior defasagem linguística no contexto da Língua Portuguesa (escrita), em razão de sua perda auditiva, interferindo em todos os níveis: fonológico, semântico, morfossintático e pragmático. Somam-se a isso algumas dificuldades que os discentes surdos encontram no processo de aprendizagem da linguagem escrita: A difícil tarefa de exprimir por escrito em 
Língua Portuguesa está descrita à dificuldade de compreensão dos textos lidos (conteúdo semântico). Alguns estudiosos ainda como Ruegg, Stefani e Carnio (1999), afirmam que a maioria dos discentes surdos apresentam impedimentos para a compreensão do texto escrito apresentando como razão principal a ausência de domínio da linguagem oral. Desta forma, encontram-se impedidos da experimentação linguística apropriada durante o período de desenvolvimento da linguagem.

Refletir o mundo e a maneira como inventamos os espaços e a comunicação de modo a incluir todos os seres humanos, é o convite que nos faz a Convenção sobre os Direitos das pessoas com deficiência da ONU, que consolida a acessibilidade como princípio e direito humano fundamental. Neste sentido, reconhecer a acessibilidade como conteúdo e forma de garantia de seus demais direitos humanos universais. Sendo assim, o ato de ensinar não deve ser restrito em nenhum segmento, mas reconhecido em seu contexto e suas condições, almejando extinguir e não criar novos obstáculos. Consideramos oportuno falar que a educação dos surdos não fracassou, ela luta arduamente para alcançar resultados memoráveis e que se confronta com resultados previstos por mecanismos e relações de poderes e de saberes atuais. Assim como, quando recebemos seis alunos surdos em meio aos alunos ouvintes, pensamos, não podemos e não queremos apenas recebe-los em nossa sala de aula, queremos desenvolver um trabalho com eles, fazer parte da vida deles. Desejamos ainda, trabalhar da mesma forma como trabalhamos com alunos ouvintes, contando histórias, mergulhando em mundos diversos.

Para que isto se tornasse possível, nossa primeira atitude foi pesquisar bibliografias infantis traduzidas para a Língua Brasileira de Sinais. Para nossa surpresa encontramos um restrito número, o que já configura um problema a exigir reflexão. Diante disto, escolhemos o livro Os Ecopiratas: uma aventura em Fernando de Noronha de Berto Junqueira. Este livro conta a história de dois primos que não se suportam e precisam passar férias juntos em Fernando de Noronha. O menino não gosta da prima porque é surda. A menina por sua vez, se oferece a ensinar Libras ao seu primo. Ao final da história, será esse alfabeto que salvará o menino num submarino que está afundando. O Livro então trata sobre a importância da consciência ecológica e um jeito diferente de se comunicar.

Para o desenvolvimento do trabalho, realizamos a interação mediada pela respectiva obra utilizando a Língua Brasileira de Sinais e a leitura oral. Utilizamos também auxílio da exposição em transparência e na sequência à dramatização que contou com o uso de materiais concretos para a caracterização dos personagens. Alunos surdos e ouvintes escolheram personagens ou utilizaram materiais concretos para caracterização, e então, o respectivo texto 
foi interpretado e vivenciado de maneira prática por cada participante. O objetivo central era fazer com que os alunos ouvintes e surdos pudessem desfrutar de maneira concreta o texto proposto. Formulamos ainda um questionário, com perguntas objetivas e interpretativas relacionadas ao livro citado anteriormente. Nas perguntas objetivas, os envolvidos precisariam marcar apenas "C" ou "E" o que nos levou a expressivos acertos. Na categoria interpretativa solicitamos que os alunos formulassem respostas.

Evidenciamos como retorno principalmente dos alunos surdos frases com palavras (substantivos e verbos) que demonstram compreensão do texto. No entanto, por causa da deficiência auditiva, a estrutura de suas frases possuem desvios sintáticos e gramaticais. O que nos leva a certeza que a utilização da Língua Brasileira de Sinais associada à dramatização formam um excelente par para aprimorar a compreensão de textos tanto para discentes surdos como ouvintes.

\section{CONCLUSÃO}

A luz dos fatos citados acima pode concluir que no caso da educação de discentes surdos torna-se algo mais complexo, pois persistem ideias rígidas e preconcebidas que alimentam a desigualdade pelo estigma de incapacidade. $\mathrm{O}$ sujeito surdo possui identidade e luta por direitos básicos como cidadania e educação, e empenha-se arduamente para afastar-se do conceito de "anormalidade". Ele é capaz de transformar esse conceito em normalidade a partir do momento em que é respeitado o seu direito de ser surdo, de fazer suas próprias escolhas e de frequentar uma escola que ofereça instrução bilíngue. Desta maneira, respeitando o seu direito à educação com acesso à Língua Brasileira de Sinais, porque é justamente a língua por excelência o instrumento de constituição de luta contra práticas sociais desiguais.

Concluímos que, ao utilizar a língua de sinais, produção textual e a dramatização como método para aprendizagem de leitura, a escrita resulta em benefícios na compreensão e interpretação de textos pelos respectivos discentes surdos. Evidenciamos que a habilidade do aprendizado provém da ação de implementar experiências com atividades concretas e contextualizadas. Desta forma, a nossa produção é uma maneira de alcançarmos maior compreensão e aprendizado em relação ao processo de aprendizagem de sujeitos surdos. Ressaltamos ainda que enquanto tivermos um sopro de vida a sair de nossos pulmões e fluindo em nossos corações vamos lutar pela inclusão. Vamos atrás de ouvidos generosos dispostos a ouvir e a reconhecer a importância que possui a educação na vida daqueles que 
não conseguem ouvir o cântico dos pássaros e a melodia do barulho das gotas da chuva caindo no chão.

Vamos retribuir com toda a gratidão que carregamos em nosso coração a oportunidade que a vida ofereceu a cada nascer do sol, contando história, pois acreditamos que estas libertam, criam asas e ajudam a tornarmos pessoas melhores, mais humanas e nos mantêm acreditando no espetáculo partilhado por meio da palavra. Quando narramos histórias, olhamos para os nossos alunos e percebemos o quão bela é a vida. $\mathrm{O}$ ato de narrar histórias não se limita apenas em proferir palavras bonitas, contar histórias é ter ciência do valor do outro, é partilhar, é comunhão e, acima de tudo é encontro de almas.

Quando decidimos ser professora e em nossa prática ser contadora de histórias ganhamos muitos amigos e chegamos à conclusão que acreditar no potencial da literatura e das crianças é definitivamente crer que existe sempre uma nova chance, uma nova oportunidade e a esperança que tudo pode ser diferente basta que acreditemos.

\section{REFERÊNCIAS}

ALVES, C. N. Recursos humanos. In: Alves, C. N. Educação inclusiva no Brasil. Portugal: Banco Mundial, 2003, p. 1-22, Disponível em: http://www.acessibilidade.net/at/kit2004/programas\%20CD/ATs/cnotinfor/Relatorio_Inclusiv a/pdf/Recursos_humanos_pt.pdf. Acesso em: 27 ago. 2018.

AMOSSY, Ruth. Imagens de si no discurso: a construção do ethos. 1. Ed., $1^{\text {a }}$ reimpressãoSão Paulo: Contexto, 2008.

BANDINI, Heloisa Helena Motta; OLIVEIRA, Claudia Lessa de Azevedo Corrêa de e SOUZA, Érika Costa de. Habilidades de leitura de pré-escolares deficientes auditivos: letramento emergente. Paidéia (Ribeirão Preto), Abr 2006, vol. 16, n 33, p. 51-58.

BRASIL. Presidência de República, Subchefia para assuntos jurídicos. Decreto $\mathbf{n}^{0}$ 5. 626 . Brasília, DF: Ministério Público, 2005.

BRASIL. Presidência de República, Subchefia para assuntos jurídicos. Decreto $\mathbf{n}^{\mathbf{0}}$ 6.949. Brasília, DF: Ministério Público, 2009ª .

BUFFA, M. J. M. B. A inclusão da criança deficiente auditiva no ensino regular: uma visão do professor de classe comum. 2002. Dissertação (Mestrado em Ciências). Hospital de Reabilitação de Anomalias Craniofaciais, Universidade de São Paulo. Bauru, 2002.

DORZIAT, Ana. Sugestões docentes para melhorar o ensino de surdos. Cadernos de Pesquisa, Nov 1999, nº. 108, p. 183- 198.

HALBWACHS, Maurice. A Memória Coletiva. Trad. Beatriz Sideau. São Paulo. Centauro, 2006. Acesso em: 22 de agosto, 2018. 
MARTINS, S.E.S. de O.; GIROTO, C. R. M. Surdez, linguagem e educação inclusiva. Educação Especial- Módulo 12. Deficiência auditiva/surdez. Disponível em: http://efpava.cursos.educacao.sp.gov.br/Resource/153528,9BA/Assets/Educa\%C3\%A7\%C3\%A3o\%20 Especial/pdf/modulo\%2004/ede_m0402.pdf. Acesso em: 22 ago. 2018.

MENDES, Enicéia Gonçalves. A radicalização do debate sobre inclusão escolar no Brasil. Revista Brasileira de Educação, dez. 2006, v. 11n33, p. 387-405.

NUNES, Benedito. O tempo na narrativa. 2. São Paulo. Ed. Ática, 1995. Acesso em: 28 de ago. 2018.

PEREIRA, M. C. da C. Leitura, escrita e surdez. Secretaria de Educação CENP/CAPE. São Paulo: FDE, 2005.

QUADROS, R. M. de; KARNOPP, L. B. Língua de sinais brasileira: estudos linguísticos. Porto Alegre: Artmed, 2004.

RUEGG, D; STEFANI, F. M; CÁRNIO, M.S. Compreensão da leitura através de interpretação oral e/ ou sinalizada de surdos inseridos no contexto de educação especial. Pró-Fono: Revista de Atualização Científica, Carapicuíba, V-11, n.2, p. 31-37, 1999.

SALLES, H. M. M. L.; FAULSTICH, E.; CARVALHO, O. L. Ensino de língua portuguesa para surdos: Programa Nacional de Apoio à Educação de Surdos- Brasília, DF: MEC; SEESP, 2004.

SASSAKI, Romeu Kazumi. Inclusão: o paradigma do século XXI. Brasília, InclusãoRevista da Educação Especial, out/2005, nº 1, p. 19-23.

SKLIAR, C. A Surdez: um olhar sobre as diferenças. Porto Alegre: Mediação. 1998.

TORRES, Vera Fátima; MAZZONI, Alberto Angel e MELLO, Anahi Guedes. Nem toda pessoa cega lê em Braille nem toda pessoa surda se comunica em língua de sinais. São Paulo: Educação e Pesquisa, Ago 2007, v. 33, n. 2, p. 369-386.

VIGOTSKI, L.S. Fundamentos de defectologia. Obras completas. Tomo cinco. Cuba: Editorial Pueblo y Educación, 1997. 